\title{
Aislamiento y caracterización de macrófagos-células espumosas a partir de aorta de un modelo de ateroesclerosis en conejo hipercolesterolémico
}

\author{
Juan Carlos Porras ${ }^{1,2}$, Clemencia Zambrano ${ }^{2}$, Darío Echeverri ${ }^{3}$, Marta Raquel Fontanilla ${ }^{1,2}$ \\ ${ }^{1}$ Laboratorio de Biología Molecular, Centro de Investigaciones, Universidad El Bosque, Bogotá, D.C. \\ 2 Departamento de Farmacia, Facultad de Ciencias, Universidad Nacional de Colombia, Bogotá, D.C. \\ ${ }^{3}$ Laboratorio de Hemodinamia Vascular, Fundación Cardiolnfantil- Instituto de Cardiología, Bogotá, D.C.
}

Actualmente existe suficiente evidencia que sustenta que la ateroesclerosis es una patología en la cual están involucrados no sólo procesos de desequilibrio y aumento de lípidos, sino también procesos inflamatorios mediados por macrófagos-células espumosas. Estos hallazgos han sido encontrados en estudios llevados a cabo con animales de experimentación. Con el propósito de racionalizar la utilización de animales y de proponer un modelo biológico alterno en el que se puedan estudiar los mecanismos de patogenicidad que involucren tipos celulares relacionados con la ateroesclerosis, en el presente trabajo se estandarizó una técnica de aislamiento y cultivo de macrófagos-células espumosas, así como, los procedimientos para caracterizar los cultivos establecidos mediante la detección de esterasas no específicas. Para el análisis de la expresión de estas enzimas, se utilizó una técnica histoquímica y electroforesis en gel de poliacrilamida en condiciones no denaturantes. En la literatura revisada, este último método no ha sido empleado para evidenciar expresión de esterasas no específicas en leucocitos. El modelo biológico aportado por este trabajo puede ser usado para estudiar respuestas de los macrófagos activados y células espumosas relacionadas con la ateroesclerosis.

Palabras clave: macrófagos-células espumosas, cultivos, ateroesclerosis, hipercolesterolemia.

Isolation and characterization of macrophages-foam cells from aorta of hypercholesterolemic rabbit

Evidence has accumulatd to support the hypothesis that atherosclerosis involves lipid imbalance as well as inflammatory responses mediated by macrophage and foam cells. These findings have been based on animal models. To rationalize animal use and to propose an alternative biological model, a technique was standardized for macrophage-foam cell isolation and culture. The cultures were characterized by non-denaturing polyacrylamide gel electrophoresis (PAGE) of nonspecific esterases and histochemical staining. This method has not been applied previously for the characterization of the non specific esterases from leucocytes. The biological model presented here can be used to study macrophage-foam cell responses related to atherosclerosis.

Key words: macrophages-foam cells, cultures, atherosclerosis, hyper-cholesterolemy.

Es reconocido que la ateroesclerosis es una de las enfermedades que afecta más personas y una

Correspondencia:

Marta Raquel Fontanilla, Transversal 9A bis No.133-25, Laboratorio de Biología Molecular, Universidad El Bosque. mrfontani@yahoo.com

Recibido: 09/0403; aceptado: 10/10/03 de las causas de muerte más frecuente en el hemisferio occidental (1). Durante mucho tiempo se consideró que la hipercolesterolemia era la causa de la ateroesclerosis; de ahí que durante décadas, las ciencias médicas buscaron métodos o tratamientos para anular o reducir los niveles altos de colesterol y lípidos $(2,3)$. Dentro de este 
marco se crearon terapias farmacológicas con medicamentos como las resinas de intercambio iónico, fibratos, ácido nicotínico y las estatinas (4-6). Debido a que el uso de hipolipemiantes no siempre controla la ocurrencia de eventos coronarios como infarto, trombosis, enfermedad coronaria aguda (ECA), etc., el estudio de la enfermedad se ha centrado en identificar otros factores asociados con su etiología (7-8).

Actualmente se sabe que, además del componente lipídico, existe una respuesta inflamatoria local que juega un papel importante en la progresión y surgimiento de complicaciones de la ateroesclerosis, como ruptura y trombosis de la placa ateroesclerótica (9). El fenómeno inflamatorio local es mediado en gran parte por la infiltración de macrófagos-células espumosas y por la síntesis y secreción de moléculas proinflamatorias por parte de éstas y otras células. De hecho, la presencia de macrófagos activados es un factor importante que incrementa la inestabilidad de la placa, su ruptura y las complicaciones finales asociadas con la enfermedad (10-12). Las razones expuestas señalan la necesidad de estudiar la forma en que estas células responden a situaciones que semejen los eventos que ocurren en la ateroesclerosis en los seres vivos.

Muchos de los hallazgos sobre el papel que los macrófagos-células espumosas tienen en la ateroesclerosis, se han encontrado en estudios llevados a cabo con animales de experimentación, como conejos, ratas, ratones y chimpancés (1314). Por ejemplo, el Grupo de Hemodinamia del Instituto de Cardiología de la Fundación CardioInfantil desarrolló un modelo de ateroesclerosis temprana (dieta de colesterol del $2 \%$ ) en conejos hipercolesterolémicos $(15,16)$. En este modelo es posible conseguir información preliminar acerca del papel de la inflamación en la ateroesclerosis y de la modulación que ejercen los medicamentos, comúnmente empleados en el tratamiento de esta enfermedad como las estatinas, sobre la hipercolesterolemia y la inflamación. Sin embargo, no es factible establecer el papel que cumplen subpoblaciones celulares específicas. De ahí que para analizar los eventos celulares y moleculares que determinan la respuesta del macrófago en el proceso ateroesclerótico, sea necesario aislar estas células.

El avance de las técnicas de cultivo ha permitido cultivar diversos tipos de células eucarióticas, entre ellas, los macrófagos. Son varios los reportes acerca de métodos de aislamiento y cultivo de macrófagos-células espumosas (17-20). Con macrófagos-células espumosas cultivadas, se ha demostrado que estas células alteran la producción de óxido nítrico en los vasos, al mismo tiempo que son productoras de especies reactivas de oxígeno como superóxidos y peróxidos. Igualmente, que estos productos celulares modulan la degradación de la matriz asociada con la inestabilidad de las placas ateroescleróticas (21).

Efectos de los inhibidores de la 3-hidroxi-3metilglutaril-CoA reductasa (HMG-CoA reductasa), diferentes al hipolipemiante, también han sido estudiados empleando cultivos celulares. Yoshida y colaboradores reportaron que la cerivastatina modula la interacción monocito-célula endotelial bajo condiciones de flujo fisiológicas (22). Sakai et al. encontraron que la simvastatina y la pravastatina suprimen el crecimiento de macrófagos inducido por lipoproteínas oxidadas de baja densidad (ox-LDL) (10). Con macrófagos alveolares y células endoteliales se estudió la regulación por la cerivastatina de la respuesta inflamatoria subsecuente a infección con Chlamydia pneumoniae (23). Luan y colaboradores encontraron inhibición de la secreción de metaloproteinasas 1,2 y 3 en cultivos de macrófagos aislados de granulomas cutáneos de conejos hipercolesterolémicos, tratados con estatinas (24).

Con el propósito de contar con un modelo biológico ex vivo en el cual sea posible estudiar los efectos que las estatinas tienen sobre los macrófagoscélulas espumosas, en el presente trabajo obtuvimos y caracterizamos cultivos primarios de macrófagos-células espumosas a partir de placas ateroescleróticas de aorta toráxica obtenida de un modelo de conejo hispercolesterolémico. EI modelo animal fue desarrollado paralelamente, en un trabajo diferente, por el Laboratorio de Hemodinamia de la Fundación CardioinfantilInstituto de Cardiología (15). 


\section{Materiales y métodos}

\section{Población objeto de estudio}

Los fragmentos de aorta utilizados para el aislamiento de los macrófagos-células espumosas se obtuvieron de conejos hipercolesterolémicos (dieta de colesterol al $2 \%$ ), con valores de colesterol séricos superiores a $300 \mathrm{mg} / \mathrm{dL}$, que hacían parte de un estudio diferente llevado a cabo por un investigador de nuestro grupo (15). Una vez realizada la eutanasia de los animales, bajo sedación (ketamina $7 \mathrm{mg} / \mathrm{kg}$ - xylazina $1 \mathrm{mg} / \mathrm{kg}$ por vía intramuscular), con sobredosis de pentotal por vía intravenosa $(25 \mathrm{mg} / \mathrm{kg})$ y aislada la aorta toráxica y abdominal, tomamos para nuestro estudio segmentos de $2 \mathrm{~cm}$ de aorta toráxica. El total de las muestras empleadas fue de 17, correspondientes a animales diferentes.

\section{Método de aislamiento y cultivo de macrófagos-células espumosas}

Inicialmente, para aislar los macrófagos-células espumosas aplicamos la metodología reportada por Naito et al. (17). Debido a que cuando se seguía este procedimiento en la primera recolección del pellet todos los macrófagos ya se habían aislado, decidimos utilizarlo eliminando los pasos subsiguientes. La íntima y la media del segmento de aorta con dimensiones de $1 \times 1 \mathrm{~cm}$ fueron separadas de la adventicia, esta última fue desechada, y cortadas en pequeños fragmentos de aproximadamente $1 \times 1 \mathrm{~mm}$. Para facilitar la liberación de más células de la íntima, los fragmentos se colocaron en platos de cultivo de 24 pozos (Falcon) y se incubaron durante dos horas con colagenasa tipo II (Sigma) al 0,3\% en DMEM (Gibco) libre de suero fetal bovino (SFB), a $37^{\circ} \mathrm{C}$ y $5 \%$ de $\mathrm{CO}_{2}$. Transcurrida la incubación, el sobrenadante (que contenía los explantes y la colagenasa) fue retirado y los pozos cubiertos con solución amortiguadora de fosfatos (PBS, pH 7,2). El sobrenadante se centrifugó a 800 rpm por 5 minutos y el precipitado obtenido se sometió, en los mismos pozos empleados para la digestión con colagenasa una vez removido el PBS, a una digestión con elastasa (Sigma) al 0,05\% y se volvió a incubar por una hora a $37^{\circ} \mathrm{C}$ en $5 \%$ de $\mathrm{CO}_{2}$. Pasado este tiempo, el sobrenadante fue retirado y se realizaron tres lavados con PBS dejando los fragmentos de íntima dentro de los pozos. Para promover la dispersión completa de las células que permanecían en los fragmentos de íntima, se utilizó colagenasa fresca $(0,3 \%)$ y se pipeteó suavemente con micropipeta durante 15 minutos por tres veces y se dejó en incubación por 30 minutos. Posteriormente, los pozos se lavaron tres veces con DMEM y el sobrenadante y los fragmentos de arteria fueron desechados; las células que permanecieron adheridas a la superficie de los platos, que corresponden a macrófagos-células espumosas, se incubaron con DMEM suplementado con antibióticos (penicilina sódica $100 \mathrm{U} / \mathrm{ml}$ y amikacina $100 \mathrm{mg} / \mathrm{ml}$ ) hasta por seis días. Las células que durante el proceso se adhirieron a la superficie de los pozos, representaron la población de macrófagos activados y células espumosas aisladas de las placas ateroescleróticas. Todos los procedimientos se llevaron a cabo en condiciones estériles.

\section{Caracterización histoquímica de los cultivos} de macrófagos-células espumosas

Para realizar la identificación y caracterización en cultivo de las células aisladas se llevó a cabo la tinción de esterasas no específicas (25). En este procedimiento, las células adheridas se lavaron con PBS antes de ser expuestas a una mezcla formalina-acetona (25:75) en PBS, pH 6,6, con el fin de fijarlas al plato de cultivo. Luego de su fijación, los cultivos se incubaron durante 45 minutos a temperatura ambiente con la siguiente mezcla previamente filtrada: $9,5 \mathrm{ml}$ de solución amortiguadora de fosfatos $0,06 \mathrm{M} ; 0,05 \mathrm{ml}$ de una solución de pararosanilina clorhidrato hexazotizada [pararosanilina clorhidrato (SIGMA), $\mathrm{HCl}$ conc., $\mathrm{NaNO}_{2}$ ] y $10 \mathrm{mg}$ de $\alpha$-naftil-butirato (SIGMA) en $0,5 \mathrm{ml}$ de una mezcla 1:1 de etilenglicol y etil éter. Antes de emplear la mezcla, se debió ajustar el $\mathrm{pH}$ de la misma a un valor de 6,3. Después de finalizado el tiempo de tinción, los pozos se lavaron con agua tres veces y se llevó a cabo la tinción de contraste con una solución de verde de metilo al $1 \%$ durante dos minutos. Posteriormente, se realizaron lavados con agua hasta retirar el exceso de colorante y se dejó secar al aire libre. La actividad de la enzima fue evidenciada por la aparición de color rojo sobre la membrana celular de los macrófagos y de las células espumosas, 
también por la presencia de gránulos rojos en el citoplasma de las células $(25,26)$.

Como control positivo de este experimento se emplearon monocitos aislados de sangre periférica de los conejos en estudio, debido a que estas células expresan esterasas no específicas $(27,28)$. Se incluyeron como control negativo cultivos primarios de fibroblastos humanos aislados de piel por investigadores en nuestro laboratorio (29).

\section{Aislamiento de los monocitos de sangre de conejo empleados como control positivo en la determinación de las esterasas no específicas}

El aislamiento de monocitos de sangre de conejo se realizó para obtener las células que en este trabajo sirvieron como control positivo para la tinción de esterasas no específicas (30). Brevemente, se tomaron $20 \mathrm{ml}$ de sangre en dos tubos heparinizados y se mezclaron suavemente por inversión. Luego, se centrifugaron a 2500 rpm durante 10 minutos, se tomaron los leucocitos (capa de color blanco lechosa) y se colocó $1 \mathrm{ml}$ en cada tubo estéril de $15 \mathrm{ml}$. En este momento, a cada uno de los tubos se le adicionó $1 \mathrm{ml}$ de medio RPMI (Gibco BRL, Life Technologies). En otros dos tubos se colocaron $6 \mathrm{ml}$ por tubo de Ficoll-Histopaque (Lymphocyte Separation Médium; ICN Biomedicals Inc.) en una proporción 3:1 con relación al volumen extraído de los tubos heparinizados, esta relación de mezcla Ficollleucocitos se escogió debido a que la relación (2:1) reportada por los autores (30), no funcionó con la sangre de los conejos hipercolesterolémicos. Lentamente se les adicionó la mezcla plasma- RPMI por las paredes del tubo. Posteriormente, se procedió a centrifugar a 1.800 rpm por 30 minutos. El anillo de color blanco formado por los leucocitos se retiró colocándose en tubos Eppendorf, a los cuales se les adicionó $1 \mathrm{ml}$ de RPMI y se centrifugó a 2.600 rpm por 3 minutos. Este procedimiento de lavado se repitió tres veces. Finalmente, los pellets se reunieron en uno solo y se resuspendieron en RPMI suplementado al $10 \%$ con SFB (Gibco). Esta suspensión celular se sembró en platos de cultivo de 24 pozos (Falcon) y se incubó por tres horas a $37^{\circ} \mathrm{C}$ y atmósfera húmeda de $5 \% \mathrm{CO}_{2}$. Luego, se hicieron dos lavados con PBS permaneciendo adheridos al plato solamente los monocitos, los cuales fueron cultivados en RPMI suplementado con antibióticos, para ser empleados posteriormente como control positivo en la caracterización histoquímica de las células aisladas.

\section{Detección mediante electroforesis en gel de poliacrilamida (PAGE) de esterasas no específicas obtenidas de los macrófagos- células espumosas}

Se colocaron macrófagos-células espumosas aislados de las arterias de los conejos en solución amortiguadora de lisis (Tris $10 \mathrm{Mm}$, EDTA $1 \mathrm{Mm}$, $10 \mathrm{mM} \mathrm{NaCl}$ ) y sometidos a periodos de congelación y descongelación con el propósito de lisar las células. Posteriormente, las muestras se centrifugaron a $6.000 \mathrm{rpm}$ y el sobrenadante se transfirió a tubos limpios. La concentración de proteínas presentes en el sobrenadante se determinó mediante el método de Bradford. Para realizar la electroforesis, $25 \mathrm{mg}$ de proteína total se separaron en geles de poliacrilamida $10 \%$ en condiciones no denaturantes en solución amortiguadora TBE 1X (Tris $68 \mathrm{mM}$, ácido bórico $88 \mathrm{mM}$ y EDTA $2 \mathrm{mM}$, pH 8,0). Se realizaron dos geles de igual concentración en los cuales se hicieron siembras idénticas con el propósito de emplear uno de los geles en la detección de la actividad enzimática y el otro para hacer tinción de proteínas con azul de Coomassie. La electroforesis se corrió a voltaje constante de 80 voltios a temperatura constante. Para visualizar proteínas con actividad esterasa no específica, los geles se incubaron con una solución preparada mezclando $\alpha$-naftil butirato en acetona-agua y fast blue en solución tampón Tris $\mathrm{HCl} 0,75 \mathrm{M}$, pH 6,8 (31). La reacción enzimática de tinción se llevó a cabo en oscuridad y se detuvo después de una hora empleando una mezcla de ácido acéticometanol-agua. Como controles positivo y negativo se emplearon extractos proteicos de papa y fibroblastos, respectivamente.

\section{Resultados}

\section{Estandarización del método de aislamiento de los macrófagos-células espumosas}

El aislamiento, el cultivo y la caracterización in vitro de macrófagos-células espumosas fue el 
objetivo principal del presente trabajo. Según el procedimiento descrito en materiales y métodos, se establecieron cultivos primarios que pudieron mantenerse hasta por seis días, tiempo durante el cual se realizó su caracterización histoquímica. En total, se procesaron 17 aortas disectadas de conejos hipercolesterolémicos y en todos los casos fue posible aislar y cultivar macrófagoscélulas espumosas. La cantidad promedio de estas células por cultivo, obtenida al contar diez

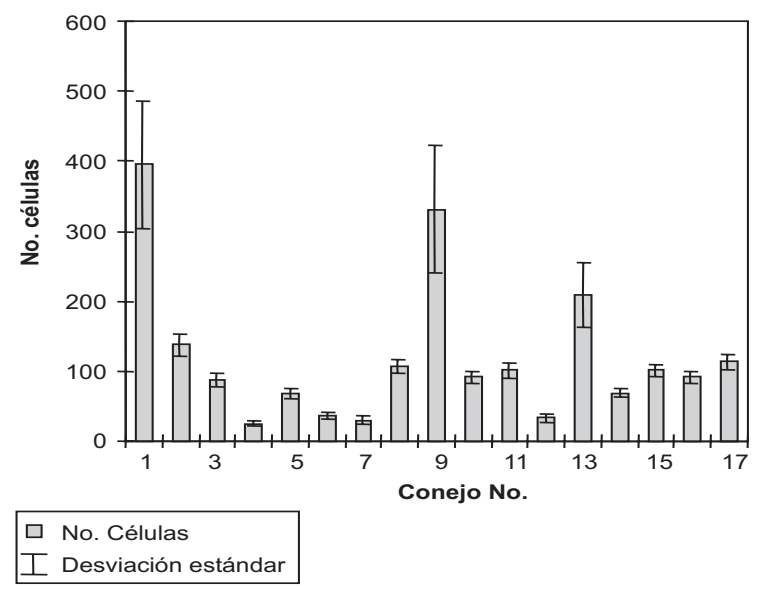

Figura 1. Número de células obtenidas por cultivo. En cada uno de los cultivos establecidos se escogieron 10 campos al azar. En cada campo se contó el número de células y se obtuvo un promedio de los valores obtenidos. Los datos en la gráfica corresponden a los promedios obtenidos para cada cultivo \pm la desviación estandar. campos con el microscopio invertido, y su respectiva desviación estándar se presentan en la figura 1.

La figura 2 muestra la apariencia de un cultivo que se hizo aprovechando la habilidad que tienen los macrófagos activados y las células espumosas de adherirse a la superficie del plato de cultivo, cuando se realizan digestiones enzimáticas con colagenasa y elastasa en ausencia de SFB. Como se observa en la figura, hay diferencias en el tamaño de las células sembradas; se nota la presencia de células grandes (células espumosas) y de células más pequeñas con morfología similar a la descrita para macrófagos cultivados.

\section{Caracterización histoquímica de esterasas no especificas}

La caracterización histoquímica de los cultivos se realizó estableciendo la presencia de esterasas no específicas en los macrófagos activados y células espumosas. La figura 3 contiene imágenes de los cultivos antes (panel $A$ ) y después de la tinción (panel B). En ambos paneles, al igual que en la figura 1, se aprecian células de varios tamaños, incluso células grandes. Nótese que la membrana de las células cultivadas efectivamente se tiñe de color rojizo (panel B). Sin embargo, llama la atención el hecho de que las células grandes exhiben una coloración localizada centralmente, diferente a la observada en los macrófagos activados pequeños y los monocitos.

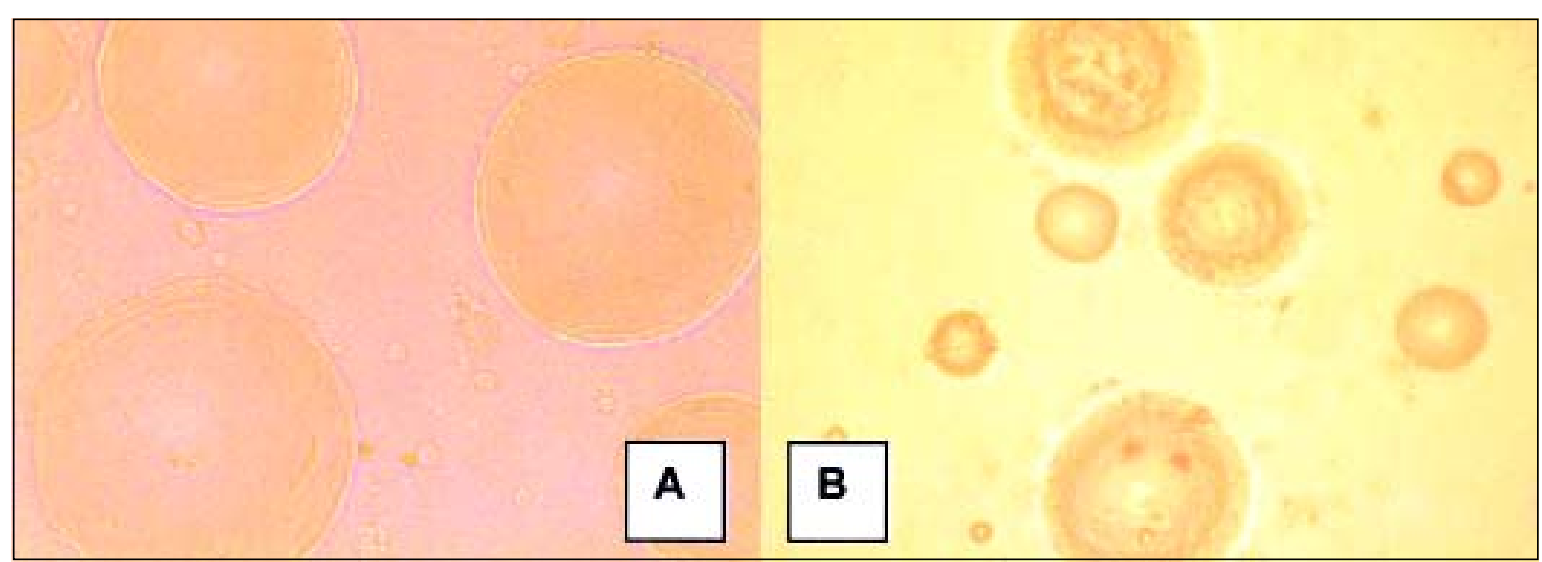

Figura 2. Macrófagos-células espumosas en cultivo. Se aislaron y cultivaron macrófagos-células espumosas, según la metodología descrita en el texto. La figura corresponde a una fotografía tomada con un microscopio de luz invertido. Los paneles A y B presentan cultivos establecidos a partir de muestras diferentes; obsérvese la morfología diversa de las células. 40X. 


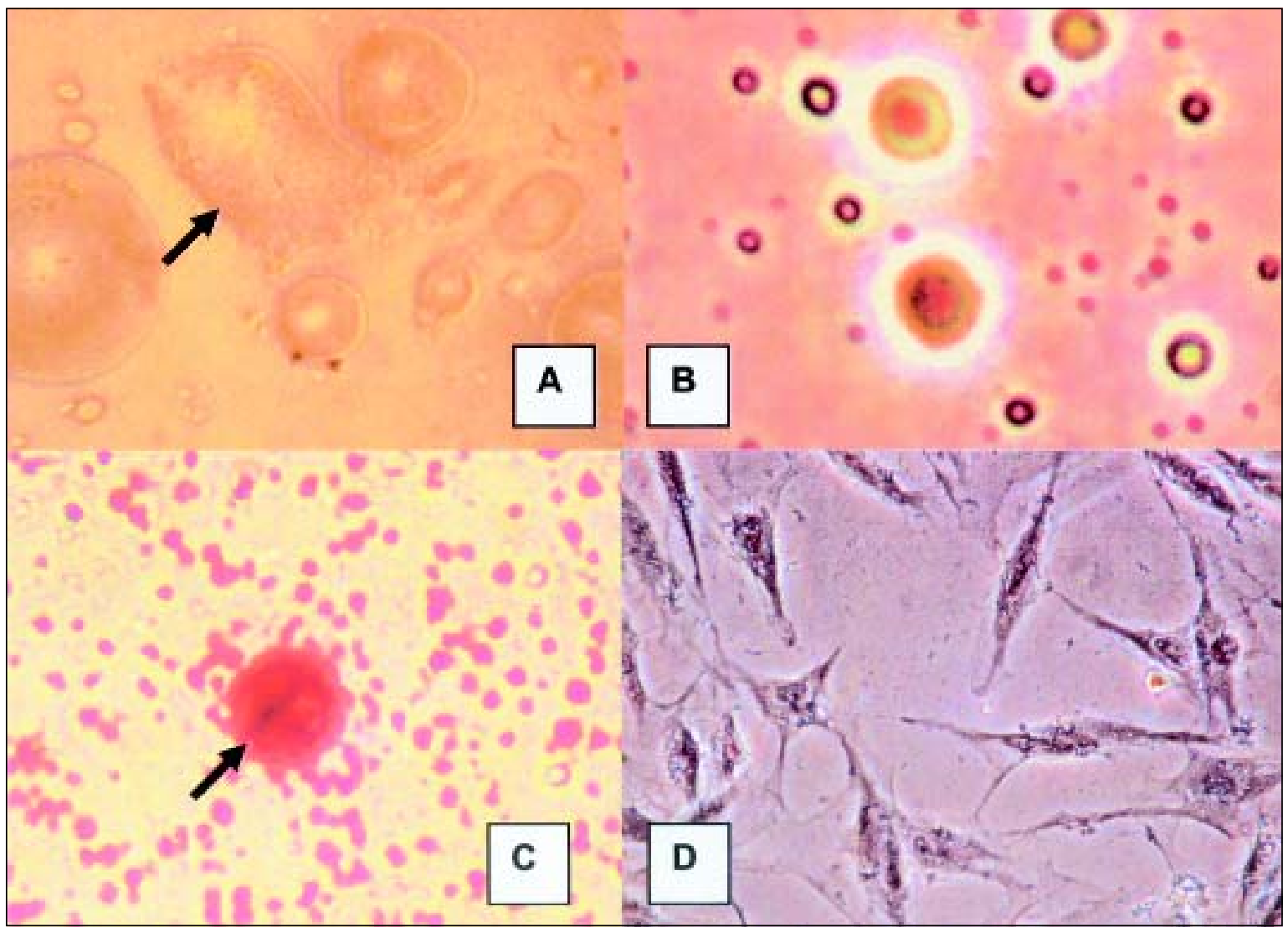

Figura 3. Detección histoquímica de esterasas no específicas en macrófagos y células espumosas cultivados. A cultivos de macrófagos activados-células espumosas incubados por tres días, se les determinó la actividad esterasa no específica. Panel A: cultivo sin teñir, la flecha incluida en la figura señala una célula completamente adherida al plato de cultivo (40X). Panel B: cultivo sometido a la tinción (40X). Panel C: control positivo, monocitos cultivados por un día sometidos a la tinción (100X). Panel D: control negativo, cultivo primario de fibroblastos (40X).

En el monocito indicado con la flecha en el panel $\mathrm{C}$, la tinción cubre homogéneamente la superficie celular. En la figura también se ve la fotografía de un cultivo primario de fibroblastos aislados de dermis humana que fue empleado como control negativo (panel D).

\section{Detección de esterasas no especifícas mediante electroforesis en gel de poliacrilamida (PAGE) en condiciones no denaturantes}

Decidimos emplear PAGE como método alterno de detección de esterasas no específicas en los macrófagos-células espumosas aislados. La figura 4 muestra una de las electroforesis realizadas. El panel A corresponde a la parte del gel expuesta al sustrato y el panel $B$, a la porción que fue teñida con azul de Coomassie. El carril uno del panel A muestra la separación del extracto proteico de macrófagos activados y células espumosas; el carril dos, la separación de la muestra incluida como control negativo (extracto de proteínas de fibroblastos) y el carril tres la separación del control positivo (extracto proteico de papa). Como se observa, tanto el control positivo como el aislado proteico de macrófagos contienen proteínas con actividad esterasa no específica. El panel B muestra los resultados obtenidos con el gel revelado con azul de Coomassie. El carril marcado como MP contiene el marcador de peso; el carril uno, extracto proteico de fibroblastos cultivados (control negativo); el carril dos, extracto proteico de macrófagos cultivados, y el tres, el extracto proteico de papa (control positivo). 

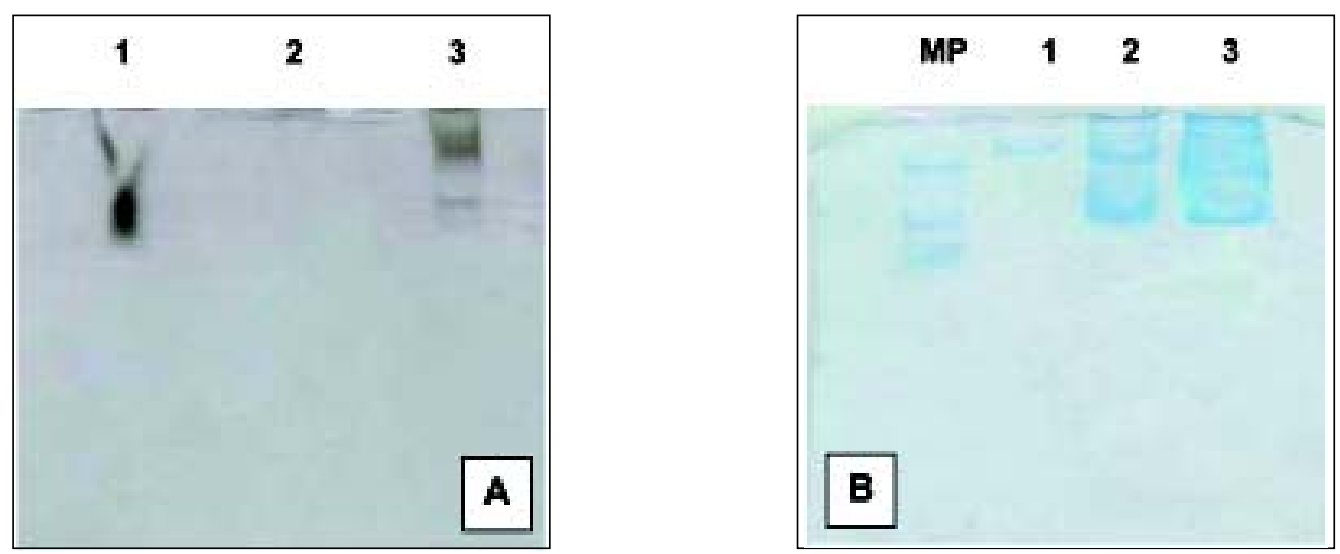

Figura 4. Electroforesis en gel de poliacrilamida en condiciones no denaturantes de los extractos proteicos celulares. Cultivos de macrófagos y células espumosas incubados por tres días fueron lisados y las proteínas extraídas y analizadas en geles de poliacrilamida al $10 \%$ en condiciones no denaturantes. Para la electroforesis, se emplearon 20 mg de proteínas totales. La detección de las esterasas no específicas se realizó empleando una solución fresca de $\alpha$-naftil butirato y fast blue como sustrato por 45 minutos, en ausencia de luz y a temperatura ambiente. Panel A: gel incubado con el sustrato de las esterasas no específicas (fast blue - $\alpha$-naftil-acetato). El carril 1 corresponde al análisis del extracto proteico de los macrófagos y células espumosas cultivadas; el carril 2, a la muestra de proteínas aisladas de fibroblastos (control negativo); el carril 3 contiene el aislado proteico de papa empleado como control positivo. Panel B: gel teñido con azul de Coomassie. El carril MP corresponde al marcador de peso molecular; el carril 1, a la muestra de proteínas aisladas de fibroblastos; el carril 2, al extracto proteico de los macrófagos y células espumosas aisladas y cultivadas; el carril 3, al extracto de proteínas de papa.

Puede observarse que para el control positivo y para las muestras de los extractos proteicos celulares (macrófagos-células espumosas) aparece una banda en la misma región, mientras que para el control negativo no se distingue ninguna banda.

\section{Discusión}

El contar con un método de cultivo de macrófagoscélulas espumosas aislados de placas ateroescleróticas facilita el estudio de efectos diferentes al hipocolesterolemiante de inhibidores de la HMG-CoA reductasa. Los métodos reportados de cultivo de estas células utilizan fuentes diferentes como cavidades alveolares y peritoneales $(10,23,32)$, granulomas cutáneos (24) y aorta $(17,21,26,33,34)$. Los procedimientos que parten de aorta emplean explantes de íntima o disgregación enzimática, con diversos tipos de colagenasas y elastasas, de fragmentos de la arteria despojada de adventicia.

Naito y colaboradores (17), quienes describieron hace varios años el empleo de íntima de aorta de un modelo de ateroesclerosis como fuente de macrófagos-células espumosas, señalan que estas células pueden distinguirse de otros tipos celulares presentes en la lesión ateroesclerótica por dos características: primero, la habilidad que tienen de adherirse al plato de cultivo en presencia de colagenasa y elastasa; segundo, la tinción positiva para esterasas no específicas. En nuestro trabajo, partimos del método reportado por estos autores. Sin embargo, en la aplicación del mismo introdujimos modificaciones que simplificaron la técnica de Naito et al. La primera de éstas fue ayudar mecánicamente a la digestión enzimática, pipeteando suavemente cada 15 minutos. La segunda modificación consistió en eliminar los últimos pasos de lavados-centrifugacionesresuspensiones contemplados en este protocolo, debido a que nuestras observaciones al microscopio mostraron ausencia de células. Las características morfológicas de las células aisladas y cultivadas por nosotros son compatibles con las descritas en los trabajos del grupo de Naito y otros grupos para macrófagos-células espumosas en cultivo $(14,17,34)$. Este resultado junto con los datos obtenidos en la determinación de esterasas no 
específicas, confirman que las células aisladas y cultivadas de lesiones ateroescleróticas corresponden a macrófagos activados y células espumosas. Nosotros escogimos emplear la tinción de esterasas no específicas sobre otras reportadas, debido a que con el procedimiento de aislamiento utilizado las únicas células que se pueden adherir al plato y teñir son macrófagos y células espumosas. De modo que, aunque esta tinción puede ser positiva para otro tipo de leucocitos, en el contexto de nuestro trabajo la tinción positiva específicamente identificó macrófagos-células espumosas.

En general, en los cultivos que realizamos se observa una cantidad relativamente pequeña de células. Lo anterior puede deberse en parte, a que los macrófagos activados y las células espumosas se concentran principalmente en el área de la lesión ateroesclerótica y no a lo largo de todo el endotelio. Por lo tanto, las células que se pueden aislar de una arteria dependen del número de placas presentes en el segmento aórtico y de la cantidad de células que se encuentran en cada placa. En los artículos revisados que describen métodos de aislamiento de macrófagos-células espumosas, solo Naito y colaboradores comentan aspectos relacionados con la baja cantidad de células obtenidas. Nuestros resultados no contradicen esos hallazgos.

Otra característica de los cultivos que establecimos es la ausencia de proliferación celular y la disminución del número de células con el tiempo. Debido a que los macrófagoscélulas espumosas en cultivo son células completamente diferenciadas con una vida media menor de siete días (17), no se debe esperar su proliferación in vitro. Infortunadamente, la baja celularidad vista en los cultivos puede limitar su utilización como modelo biológico en la evaluación de la expresión génica, debido a que algunas técnicas accesibles necesitan muestras representativas del material que se desea analizar. No obstante, el empleo de segmentos aórticos más grandes, posiblemente ayude a incrementar la cantidad de macrófagos-células espumosas obtenidas y, por ende, la concentración de las macromoléculas de interés.
Investigaciones anteriores reportaron el empleo de la tinción con $\alpha$-naftil butirato y pararosanilina hexazotizada para establecer la presencia de esterasas no específicas en cortes histológicos de arteria lesionada y en cultivos de macrófagoscélulas espumosas $(26,36,37)$. Los resultados de los análisis histológicos indican una distribución heterogénea de las esterasas no específicas en los macrófagos-células espumosas. Así, cuando los cultivos fijados fueron expuestos a la mezcla $\alpha$-naftil butirato y pararosanilina hexazotizada en las células pequeñas la coloración fue intensa y homogénea en la superficie observable. Por el contrario, las células grandes exhibieron una coloración púrpura menos intensa y localizada principalmente hacia la parte central del citoplasma. El patrón de coloración de las células pequeñas coincide con el del control positivo (monocito), pero el de las grandes no.

La explicación para este fenómeno puede residir en el hecho de que en los macrófagos activados y células espumosas, se establece un equilibrio dinámico entre la hidrólisis y la reesterificación del colesterol (34). Así, cuando hay una disminución de aceptores de colesterol como HDL o cuando dichos aceptores son insuficientes con relación a la cantidad de colesterol, el equilibrio favorece la esterificación y, entonces, se acumulan ésteres de colesterol en el citosol de los macrófagos, lo cual conduce a la formación de células espumosas. Existen diferencias en los niveles enzimáticos de esterificación y desesterificación del colesterol en macrófagos activados-células espumosas (34). Creemos que la expresión de esterasas no específicas está relacionada con ese fenómeno. Por esta razón, las células pequeñas con tinción fuerte y uniforme en la superficie (hipotéticamente con mayor actividad esterasa) presentan menor acumulación de colesteril ésteres. Por el contrario, las células grandes con coloración menos intensa y localizada exhiben menor actividad esterasa. Lo anterior puede estar conduciendo a una menor actividad hidrolítica y a la consiguiente acumulación de lípidos. Para probar lo anterior, se requieren experimentos que cuantifiquen la actividad hidrolítica (actividad esterasa) en células pequeñas y en células grandes. Igualmente, experimentos 
que relacionen los patrones de tinción que observamos con los datos de las cuantificaciones. El establecimiento que hicimos de la técnica de detección de esterasas no específicas mediante PAGE, puede ser de utilidad en la cuantificación propuesta. Esta es una contribución novedosa de nuestro trabajo ya que en la literatura revisada, la detección de esterasas no específicas por este método ha sido reportada para leucocitos circulantes (25), no para macrófagos diferenciados y células espumosas; además, su realización es rápida y práctica ya que evita el hecho de mantener las células en cultivo por varios días y todo lo que esto demanda.

Los datos presentados indican la obtención de cultivos celulares que pueden ser empleados para estudiar diferencias en la expresión de genes en los macrófagos activados-células espumosas, cuando son expuestos a atorvastatina in vivo e in vitro. Problemas como la baja celularidad obtenida, se pueden superar aumentado el tamaño de las muestras de aorta lesionadas utilizadas para el aislamiento.

\section{Agradecimientos}

Queremos expresar nuestros agradecimientos a Félix Montes y Mónica Porto del Laboratorio de Hemodinamia Vascular de la Fundación CardioInfantil por su colaboración en el manejo de los conejos y la obtención de las muestras. A Carmen Lucía Roa de la Facultad de Medicina de la Universidad El Bosque por las muestras y reactivos, a Arturo Liévano de la Facultad de Ingeniería de la Universidad El Bosque por su colaboración en la toma de las fotos, a Marina Caro de la Universidad Nacional de Colombia por los reactivos facilitados para realizar los ensayos y a Johana Polanía del Departamento de Informática de la Universidad El Bosque por su valiosa colaboración en el diseño e impresión de este artículo.

\section{Referencias}

1. Fuster V. Epidemic of cardiovascular disease and stroke: the three main challenges. Circulation 1999;99: 1132-37.

2. LaRosa J. Prevention and treatment of coronary heart disease: who benefits? Circulation 2001;104:1688-92.
3. Anderson J, Davidson M, Blonde L, Brown V, Howard J, Ginsberg $\mathrm{H}$ et al. Long-term cholesterollowering effects of psyllium as an adjunct to diet therapy in the treatment of hypercholesterolemia. Am J Clin Nutr 2000;71:1433-8.

4. Gaw A, Packard C, Lindsay G, Murray E, Griffin B, Caslake $M$ et al. Effects of colestipol alone and in combination with simvastatin on apolipoprotein B metabolism. Arterioscler Thromb Vasc Biol 1996;16: 23649.

5. Staels B, Dallongeville J, Auwerx J, Schoonjans K, Leitersdorf E, Fruchart JC. Mechanism of action of fibrates on lipid and lipoprotein metabolism. Circulation 1998;98:2088-93.

6. Gotto AM Jr. Lipid lowering, regresion and coronary events. Circulation 1995;92:646-56.

7. Sacks F, Moye L, Davis B, Cole T, Rouleau J, Nash D, Pfeffer M, Braunwald E. Relationship between plasma LDL concentrations during treatment with pravastatin and recurrent coronary events in the cholesterol and recurrent events trial. Circulation 1998; 97:1446-52.

8. Lessner S, Prado H, Waller E, Galis Z. Atherosclerotic lesions grow through recruitment and proliferation of circulating monocytes in a murine model. Am J Pathol 2002;160:2145-55.

9. Ambrose J, Martínez E. A new paradigm for plaque stabilizatlon. Circulation 2002;150:2000-10.

10. Sakai M, Kobori S, Matsumara T, Biwa T, Sato Y, Takemura T, Hakamta H, Horiuchi S, Shichiri M. HMG-CoA reductase inhibitors suppress macrophage growth induced by oxidized lipoprotein. Atherosclerosis 1997;133:51-9.

11. Hansson G. Immune mechanisms in atherosclerosis. Arterioscler Thromb Vasc Biol 2001;21:1876-90.

12. Zaltsman A, George S, Newby A. Increased secretion of tissue inhibitors of metalloproteinases 1 and 2 from the aortas of cholesterol fed rabbits partially counterbalances increased metalloproteinase activity. Arterioscler Thromb Vasc Biol 1999;19:1700-7.

13. Knowles J, Maeda N. Genetic modifiers of atherosclerosis in mice. Arterioscler Thromb Vasc Biol 2000;20:2336-45.

14. Moghadasian M, Frohlich J, McManus B. Advances in experimental dyslipidemia and atherosclerosis. Lab Invest 2001;81:1173-83.

15. Echeverri D, Montes F, Porto M, Santamaria G, O'Connor W, Moreno PR. Early improvement in endothelial-dependent relaxation is related to decreased macrophage infiltration and plaque formation in experimental atherosclerosis. J Am Coll Cardiol 2003; 41 :(Suppl.A):238. 
16. Echeverri D, editor. Modelos experimentales de aterogénesis. Manual básico de investigación experimental. Bogotá: Ediciones Médicas Latinoamericanas; 2002. p.49-70.

17. Naito M, Kuzuya M, Funaki Ch, Nakayama Y, Asai K, Kuzuya F. Separation and characterization of macrophages and smooth muscle cells in rabbit atherosclerotic lesions. Artery 1987;14:266-82.

18. Takaku M, Wada Y, Jinnouchi K, Takeya M, Takahashi $\mathrm{K}$ et al. An in vitro coculture model of transmigrant monocytes and foam cell formation. Arterioscler Thromb Vasc Biol 1999;19:2330-9.

19. Galis Z, Asanuma K, Godin D, Meng X. N-acetyl cysteine decreases the matrix-degrading capacity of macrophage-derived foam cells. Circulation 1998;97: 2445-53.

20. Vijayagopal P, Glancy L. Macrophages stimulate cholesteryl ester accumulation in cocultured smooth muscle cells incubated with lipoprotein-proteoglycan complex. Arterioscler Thromb Vasc Biol 1996;16:111221.

21. Rajagopalan S, Meng X, Ramasamy S, Harrison D, Galis Z. Reactive oxygen species produced by macrophage-derived foam cells regulate the activity of vascular matrix metalloproteinases in vitro. $\mathrm{J}$ Clin Invest 1996;98:2572-9.

22. Yoshida M, Sawada T, Ishii H, Gerszten R, Rosenzweig, Gimbrone M, Yasukochi Y, et al. HMGCoA reductase inhibitor modulates monocyteendothelial cell interaction under physiological flow conditions in vitro. Arterioscler Thromb Vasc Biol 2001; 21:1165-71.

23. Kothe H, Dalhoff K, Rupp J, Muller A, Kreuzer J, Maass $\mathbf{M}$ et al. Hydroxymethylglutaryl coenzyme A reductase inhibitors modify the inflammatory response of human macrophages and endothelial cells infected with Chlamydia pneumoniae. Circulation 2000;101: 1760-3.

24. Luan Z, Chase A, Newby A. Statins inhibit secretion of metalloproteinases $1,2,3$, and 9 from vascular smooth muscle cells and macrophages. Arterioscler Thromb Vasc Biol 2003;23:769-75.

25. Li C, Lam W, Yam L. Esterases in human leukocytes. J Histochem Cytochem 1973;21:1-12.

26. Naito M, Nomura H, Esaki T, Iguchi A. Characteristics of macrophage-derived foam cells isolated from atherosclerotic lesions of rabbits. Atherosclerosis 1997; 135:241-7.

27. Yam L, Li C, Crosby H. Cytochemical identification of monocytes and granulocytes. Am J Clin Pathol 1971; 55:283-90.

28. Malinauskas RA, Herrmann RA, Truskey GA. The distribution of intimal white blood cells in the normal rabbit aorta. Atherosclerosis 1995;115:147-63.

29. Doncel S, Pérez A, Roa CL, Fontanilla MR. Estandarización de un método de elaboración de un análogo de dermis humana. Revista Colombiana de Ciencias Químico Farmacéuticas 2001;30:9-15.

30. Ávila L, Romero C. Manual práctico de inmunología clínica. Primera edición. Bogotá, D.C.: TM Editores; 1995. p.171-2.

31. Manchenko G. Handbook of detection of enzymes on electrophoretic gels. London: CRC Press; 2002. p.179.

32. Galis Z, Sukhova G, Kranzhofer R, Clark S, Libby P. Macrophage foam cells from experimental atheroma constitutively produce matrix-degrading proteinases. Proc Natl Acad Sci USA 1995;92:402-6.

33. Rosenfeld M, Khoo J, Miller E, Parthasarathy S, Palinski W, Witztum J. Macrophage-derived foam cells freshly isolated from rabbit atherosclerotic lesions degrade modified lipoproteins, promote oxidation of lowdensity lipoproteins, and contain oxidation- specific lipidprotein adducts. J Clin Invest 1991;87:90-9.

34. Li F, Hui D. Modified low density lipoprotein enhances the secretion of bile salt-stimulated cholesterol esterase by human monocyte-macrophages. J Biol Chem 1997; 272:28666-71.

35. Aquel N, Ball R, Waldmann H, Mitchinson M. Monocytic origin of foam cells in human atherosclerotic plaques. Atherosclerosis 1984;53:265-71.

36. Walton L, Franklin I, Bayston T, Brown L, Greenhalgh R, Taylor G, Powel J. Inhibition of prostaglandin $\mathrm{E}_{2}$ synthesis in abdominal aortic aneurysms. Implication for smooth muscle cell viability, inflammatory processes, and the expansion of abdominal aortic aneurysms. Circulation 1999;100:4854.

37. Klurfeld D. Identification of foam cells in human atherosclerotic lesions as macrophages using monoclonal antibodies. Arch Pathol Lab Med 1985;109: 445-9. 